\title{
MOTIVES FOR THE STUDY OF MODERN LANGUAGES
}

\author{
Albert H. MarckWardT \\ University of Michigan
}

$T^{\prime}$ HE AIMS or objectives of modern language instruction have been under almost constant discussion in educational circles in the United States for the past fifty years. Recently our concern with this question has been intensified because of our experiences in the socalled Army language program, and more particularly because of the wave of curriculum revision now engulfing so many of our colleges and universities. Similarly in the Spanish speaking countries of this continent, the increased interest in the study of English during the war years has served to focus attention upon the same series of problems. Just what language activities are we attempting to develop? Are we to devote most of our attention to reading, writing, speaking, or hearing? It is inevitable that different objectives will call for different materials, different procedures, and will present different problems.

But before we can deal adequately or intelligently with the question of aims or objectives, there is something much more fundamental which must be understood-the motives impelling the individual, the class, or the nation to the study of modern languages, for it is only in terms of a comprehension of these motives that any set of objectives can be competently formulated and stated. Why does Johnny Smith choose French as a ninth grade subject in preference to Ancient History? Why does Juan Sanchez elect English-if his curriculum does not require him to take it? And why should his curriculum require it? To understand this we must examine not only the present but also the intellectual past of the Western European peoples.

The chief motives impelling man to learn the speech of his neighbors are five in number, three of them practical and the other two relatively non-utilitarian. We shall consider the latter first.

We may begin with the old and widespread assumption that a knowledge of modern languages is one of the accomplishments of a cultivated man, and ask ourselves what lies behind this. We must realize that when the dismemberment and decay of the Roman Em- 
pire plunged Europe into political and social chaos, there was nevertheless an intellectual unity which bound medieval Europe together. A not inconsiderable factor in this unity was the common adherence to Latin as the language of science, learning, and culture. In fact, the adherence to Latin and its resultant unity persisted and strengthened despite the political turmoil of the Dark Ages; indeed it culminated in the intellectual movement of the twelfth and thirteenth centuries which we today call Scholasticism. By this time, of course, Europe itself had again achieved a political systematization through the development of feudalism, which brought about for a time a social and cultural synthesis. It is this synthesis which Carlyle used as the theme for his Past and Present.

Eventually the medieval world disintegrated, as that of the ancients had before, and this time the intellectual unity, including its outward manifestation of language, was seriously disrupted. The breakup of feudalism was accompanied by the rise of nationalism, a development which soon resulted in the growth in importance of the vernacular languages. This took centuries and was temporarily checked by the revival of learning during the Renaissance. Even as late as the early seventeenth century Bacon hesitated to put his major works into anything but Latin, but even so, by this time the best that was being thought and said in the western world found expression through the medium of not one but many languages.

An early recognition of this multi-lingualism of culture is to be found in England, at least, in the insistence upon the Grand Tour as a fundamental part of male education. This appears to date from the sixteenth century, and early in the seventeenth we find Thomas Nashe employing the Grand Tour as the basis for the plot of his picaresque novel The Unfortunate Traveller. Milton made the journey as a part of his education, and it is noteworthy that among the earliest poetical works of his maturity was a sonnet sequence, written in Italian and dedicated to his friend Diodatti. From that time on the biographies not only of men of letters but of others as well reveal such continental contacts. The son of Lord Chesterfield received most of the now famous letters from his father while on the tour, and in this, as in many other instances, the period spent in foreign surroundings was of considerable length. Naturally it was assumed that acquisition of a number of languages would be a by-product of 
extended travel, and some preliminary preparation toward this end was given the student before beginning his journey. The important thing for us to realize, however, is the implicit denial of cultural and linguistic insularity in the education of the well-bred Englishman

In English-speaking America the tour was not so easily arranged, but nevertheless a knowledge of the French language was considered a cultural requisite even before the colonies declared their independence from the mother country. Indeed, both French and German were studied in the Academy founded in Philadelphia by Benjamin Franklin in 1749. Soon French was included in the curricula of most of the academies in the colonies of the eastern seaboard as a standard subject for girls and to a somewhat less extent for boys-an early indication, perhaps, of the traditional North American attitude of considering culture as the business of women. As the Middle West became settled during the early decades of the nineteenth century and schools were established there, the same situation prevailed.

German came into its own somewhat later, partly as a result of the tremendous impact of Teutonic culture upon the English speaking world during the nineteenth century, and more directly as a result of the influence of the Prussian school system and German university organization upon education in America.

In the Latin-American countries the situation was much the same, except that French culture outweighed the other continental influences, and consequently training in the French language received the major emphasis. In both Spanish-speaking America and in the United States, the recent mutual flowering of interest in English and Spanish respectively is justified in part on the basis of cultural interchange. For example, Dr. Restrepo-Millan, Inspector of the Teaching of Modern Languages for the Columbian Ministry of Education, speaking in Bogotá in December, 1943, permitted himself the statement that "science and culture are now speaking English." The statement may have been a bit exaggerated in the interests of his audience which was composed of English teachers, but the justification of language study upon cultural grounds is nevertheless significant.

We must not forget, however, that provision for language study within an educational system in response to this particular motive often demands that such a system be dedicated to the fostering of an intellectual aristocracy-a system which finds a prime exemplar 
in the school of pre-war England. This is not to say that democratized education with its broadened base of student participation has no concern with culture, but in an educational system which has for its primary aim the training of students for life occupations, or in one which professes its chief end to be that of developing the student so that he may participate intelligently in the affairs of the community (training for citizenship), the so-called cultural subjects tend to fall into the category of luxuries. There is just not enough time for machine-shop and civics and French, and in the light of the assumptions upon which the curriculum has been constructed, French comes to be considered the less essential subject. Moreover, as the percentage of the total youth population enrolled in the schools increases, the likelihood of actual use of these languages in either spoken or literary cultural interchange decreases, and this often becomes a focal point of attack on the part of those who are hostile to language study.

The second of the motives leading to the study of foreign language is to be found when such languages are perpetuated in linguistic islands or linguistic colonies within another speech area. In the United States, for example, there are large colonies of Germans, Scandinavians, Italians, Poles, and other smaller groups as well. Sometimes these groups are closely concentrated in the metropolitan centers, but at times they are to be found also in rural districts. Similar conditions prevail in Argentina, Brazil, and some of the other Latin-American countries.

In situations of this kind, the foreign language is perpetuated immediately after the colonization has taken place because the immigrants have not yet been able to avail themselves of the opportunity to learn the national speech. If the colony is sufficiently large and diverse in its occupations, it can virtually sustain itself in its own tongue. After it has thus sustained itself for some time, there often develops the desire to perpetuate the customs, the literature, the songs, the popular lore of the mother country-and at times loyalty to it-and instruction in the language is resorted to as a means to secure these ends.

Foreign insularism can constitute a powerful motive for the study of language, especially when it is linked with religious separatism. Germans from the Rhineland began to settle in Pennsylvania late 
in the seventeenth century, and the bulk of this migration occurred in the eighteenth. Only recently it has been estimated that in certain counties in the southeastern part of the state, sixty-five percent of the population understands Pennsylvania Dutch and thirty-five percent is able to speak it. This demonstrates what cohesion in such a foreign-language speaking group can effect. When language instruction is developed in response to this motive, it is usually begun at the primary level, not infrequently centered in parochial schools, and a practical speaking knowledge constitutes the chief objective.

On the other hand, if such communities are not sufficiently large or strong to maintain their cultural unity or identity, the tendency to perpetuate the language of the homeland is likely to be offset by a growing tendency among the younger generation to conform to the ways of life, and of course the speech of the country as a whole. In the United States this has been especially true of the later immigrant groups, from the Balkans and southeastern Europe generally, representing languages which are not culturally fashionable. Indeed one of the lamentable features of the social attitudes of the United States is a snobbishness based upon ancestry which leads, as a reaction in many people who cannot claim Mayflower or Calvert background, to the development of a sense of shame about their heritage. The Finns, for example, have given the world one of its finest epic poems, but the second generation American of Finnish descent is likely to be at great pains to conceal any knowledge he may have of his old country background or its language.

If, in countries as heterogeneous as those of English-speaking and Spanish-speaking America, we could secure a national unity but at the same time value each national culture for what it has contributed to the agglomerate whole, we might develop a powerful incentive for language study. It should be wholly natural, rather than a cause for shame and embarrassment, that a child of Polish parents would want to read the novels of Sienkewicz which thrilled his father, or that the son of a French Canadian who has settled in New England should respond to a folk song such as En Roulant Ma Boule. But this is wishful thinking rather than a description of the situation at hand.

Turning now to somewhat more immediate and practical considerations, a third motive for the study of language is to be found in the necessity of creating a political fusion or a homogeneous social 
unit, usually as a result of conquest, although not infrequently as a result of colonization by hetero-lingual groups. In the event of the conquest, by a people speaking one language, of a people speaking another, the imposition of the language of the conquerors may be an involuntary result of the necessity of doing business together, or it may be a conscious attempt at cultural extermination, as was the case with the imposition of German upon the Poles in Posen and upon the Czechs in Bohemia. Ironically enough, conscious attempts at linguistic imposition usually meet with either open or secret resistance, whereas if the conquerors had a little more patience they would find the conquered people learning the politically dominant language out of sheer necessity.

Not always, however, does the language of the conquerors permanently prevail. It did in Romance-speaking Europe, as a result of Roman colonization, but when the Scandinavians moved into northern France, they did not succeed in imposing their language upon the conquered French, nor for that matter did their Norman descendants permanently impose French, when they overran England a few generations later.

In situations of this kind, bilingualism has sometimes been the result, as in Belgium, French Canada, and the Union of South African Republics, but in all of these instances, the area or number of speakers involved was relatively small. Occasionally along the border between two countries speaking different languages, bilingualism may be seen as a necessary first step to securing cultural homogeneity. The recognition of this by the various states along the Mexican border has led to the compulsory study of both Spanish and English in the schools of Texas, New Mexico, and Arizona, so that a sharp line of social and cultural differentiation may not develop.

In the new world the conquerors have generally tended to impose their western European tongues upon peoples speaking languages of a non-Indo-European character-to which Mexico's encouragement of the use of the indigenous languages as a vehicle for communication in matters pertaining to agriculture, public health, and government stands as a notable exception. In general the assumption has been that a single language is the vehicle necessary to secure homogeneity of culture-an assumption which in the United 
States received a tremendous impetus during the first World War, when it was discovered that foreign speaking groups often constituted centers of seditious activity, and that the members of such groups had not assimilated the social attitudes and political ideals which were felt necessary to make them into good citizens. Ever since that time instruction in the language has been one of the basic features of the Americanization program in the United States.

Usually the aims of language instruction motivated in this fashion are minimal; it is merely hoped to give the individual a practical command of the language necessary to satisfy the most elementary needs of communication. It constitutes a program to be attained outside rather than inside the regular school curriculum, and is essentially one of adult education. When education is as widespread as it is in the United States, succeeding generations can be depended upon to bring up the level of attainment.

Trade and colonization constitute a fourth motive for the study of foreign languages. If you want to do business with a people, you can do it best in their language. This is an axiom that the Germans learned and applied to their Latin-American trade relations long before the English-speaking peoples were aware of its importance It has been quite general the world over for the seller to learn the buyer's language, although in instances where the two languages involved were widely disparate, such trade jargons as Pidgin English and Beach la Mar have developed.

Countries with densely populated foreign speaking colonial possessions have also been forced into the necessity of learning the languages of the people whom they govern, especially when trade rather than colonization was the primary aim of their territorial expansion. It is interesting to observe in this connection that the eastern seaboard of the United States was settled by the English, whose primary purpose was colonization, whereas what is now the Middle West was held by the French, chiefly in the interests of trade. Yet the French left behind them far more distinguished works on the various languages of the American Indians than did the English, pointing to the obvious conclusion that commerical necessity operated as a prime motive in learning these languages.

However, except for Spanish and Portuguese as a necessity for Latin-American commercial relations, trade and colonization as mo- 
tives tend to the study of the out-of-the-ordinary rather than the more usual languages. It has led to the development of such splendid organizations as the Institut des langues orientales in France, the Institut für kolonial Sprachen in Germany, and the splendid studies carried on under Daniel Jones and his colleagues in England. Aside from the very thorough mastery and often original researches carried on by those who are at the head of such organizations, trade and commerce as motives for language study are likely to stress an elementary and practical approach rather than a thorough mastery.

Scientific and technical necessity furnishes us with the final motive for the study of foreign languages. It is inevitable that progress in certain disciplines should reach a high point of development now in one country and now in another. And it is equally natural that scientists and technicians in other countries will want to know what is being thought and written by the leaders in their particular fields. It is not often that technical books and articles are assured of a sufficiently wide audience to merit the cost of translation and re-publication. Accordingly it is incumbent upon the scientist to be able to read the works in question in the language in which they are written. It should be observed that this is the very reason back of the almost universal requirement of a reading knowledge of French and German for the doctor's degree in the United States.

In a number of such fields, the English-speaking peoples have gained a temporary ascendancy. This is especially true at present in engineering, chemistry, and medicine-fields in which a knowledge of French and German was an earlier necessity. Consequently English is becoming more firmly entrenched as a pre-professional requirement in Latin America, and even those who had already entered upon their professional careers before the establishment of such a requirement are now pursuing their studies in the language, either to enable themselves to pursue current researches in their fields or because they are looking forward to further studies in the United States. In general this impulse to the study of a language leads to a reading rather than a speaking knowledge, and requires special techniques to fit the needs of particular fields of study.

The five motives for the study of foreign languages which have been considered here, namely provision of a cultural background, the influence of foreign speech islands, the necessity for political and 
cultural unification, purposes of colonization and commerce, and the necessity of reading scientific and technical works may not be a complete list-in fact the necessity of foreign language preparation for missionaries was not mentioned-but there can be no question that these constitute the principal reasons for our learning another language. Moreover, they are sufficiently varied to suggest that no single pattern or technique of instruction, no single set of aims in a language curriculum can fit these various ends, although the sad fact is that in actual practice we tend to do precisely this. Aside from an occasional course particularly designed to furnish a reading knowledge of a language, our classroom practice tends to be quite undifferentiated, no matter what the conceivable purposes of the student body, the reasons for their being in the classroom may be.

It may be repeated that the most arresting circumstance of all is the somewhat ironical consideration that the most practical and utilitarian of the aims discussed above-cultural homogeneity and commercial necessity-demand as a workable minimum the least thorough knowledge of a foreign language, whereas the most idealistic and least practical aim-cultural background-presupposes the most complete mastery of the language studied, although needless to say, this is more often an expressed objective than an accomplished fact.

At any rate, it must be clear after this analysis of motive that any discussion of the specific objectives of the foreign language curriculum must take into account the impulses which lead students to elect these subjects, and that the content of the courses and the techniques of the classroom must be planned in accordance with the motives which are responsible for these studies. 